\title{
A Freudian/Post-Freudian Reading of J.R.R.Tolkien's The Hobbit: The Bilbo-Gollum Encounter
}

Rachael Cameron

$\mathrm{J}$

RR Tolkien's 1937

children's fantasy narrative, The Hobbit, is considered by many a modern children's classic. As an adventure narrative its past and present popularity is unquestionable. The appropriation and assimilation of The Hobbit and The Lord of the Rings trilogy into non-literary forms, such as its conversion into a visual medium, its use as an advanced 'Dungeons and Dragons' roleplaying game, and the proliferation of various merchandising items, such as posters and figurines, are all evidence of the cult status afforded Tolkien's works in contemporary popular culture.

This analysis of The Hobbit was influenced by numerous factors, such as: the position and popularity of Tolkien and his works, the capacity of this oeuvre to regenerate as Middle Earth paraphernalia, as well as my primary reception of the text as a child reader who accepted Tolkien's fantasy setting at face value. My initial approach at an adult re-reading of The Hobbit was daunting, for this canonical text appeared seamless, unflawed, monolithic and therefore impenetrable to criticism. However, in the light of Freudian/post-Freudian ideas pertaining to subjectivity and identity, new and alarming textual interpretations became possible, which inevitably altered my previous view of the text. This alteration in perception was effected by an investigation of this text as a cultural artefact whose literary production encodes specific values that belong, either explicitly or implicitly, to a particular historical epoch. ${ }^{1}$ As I unveiled these values, I was able to map, analyse and critique Tolkien's conceptual framework.

Although ostensibly represented as an 'imagined' or 'fantastic' realm, The Hobbit's setting, Middle Earth, nonetheless contains encoded concerns, anxieties, values and beliefs whose social, political and philosophical resonances are as relevant in the 1990s as they were in Europe between the two World Wars. This claim will be elucidated and supported through a critical re-reading of the text framed predominantly by a psychoanalytic perspective (but also incorporating deconstructive, semiotic and political modes of enquiry) to reveal a deeply embedded and covert identity politics that must be considered problematic in relation to such contemporary terrains as postcolonialism, gender studies, class divisions and queer theory. This is because the lived experience of peripheral or marginalised groups and subjects is inevitably influenced (in different ways and on differing levels) by prescriptive power relationships that construct, establish and perpetuate a Master/Slave dialectic. This dialectic is significant as subjectivity and power are linked in the discourse of The Hobbit (and the context that produced this text) in order to reduce, marginalise and exclude peripheral subjects and groups by defining, normalising and justifying particular relations of power, domination and repression.

The Hobbit has been described by Curtis as containing 'a permanent and unquestioned hierarchy of values '(1984, p.118), while Ryan has discerned 'vestiges of a "Chain of Being"' in Tolkien's narrative (1982, p.101). The ideology of this text has parallels with the Elizabethan chain of being, as both representational models perceive the world as a totality, that is a compartmentalised, but unified whole. These views contend that every component, every 'speck of creation was a link in the chain, and every link except those at the two extremities was simultaneously bigger and smaller than another: there could be no gap' (Tillyard 1946, p.26). In other words, The Hobbit and the Elizabethan chain of being both represent the world as a single structure comprised of a hierarchy of elements and beings whose position and value within this structure is presupposed and categorised according to an object or being's innate qualities.

Tolkien's cosmology therefore 
entails relationships of similarity to both Elizabethian and medieval models of thought which is evident in the alignment of these world views. The ideology underlying the construction and configuration of Tolkien's text can be defined as a system of thought (either conscious or unconscious) based on the premise that the world, and its systems of power, are hierarchically ordered and 'fixed'. Co-extensive with this, is the notion that human beings and their identities are structurally innate, homogeneous, 'universal' and static. The textual and contextual model of the world this narrative represents therefore categorises subjects and objects as normative, 'natural', types and subtypes that are ordered according to their essential, elemental or intrinsic value. The ideological structure of this text and Tolkien's context may then be considered a 'double signifying system' (Barthes 1972, pp.109-127). At its surface level, the text (through its analogies with the Elizabethan chain of being) valorises the myth of a preindustrial, English utopia, while its deeper contents disguise an assumption of the superiority of specific beings (whose authority justifies imperialist or nationalist mythologies and imperatives) that is unable to account for racial, gendered or class distinctions and the specificities these differences entail.

The focus of this essay will concern the encounter between Bilbo Baggins and Gollum, which will be considered a critical moment of signification in the text. This textual fragment is crucial in the understanding of the ideologies outlined above, as it is through this encounter that a particular power dynamic is established and represented. This dynamic may be likened to a Master/Slave dichotomy as, through their interactions, one character attains a superior, primary position, while another character is subordinated and relegated to a secondary position of importance. In this instance, this dynamic encodes Bilbo as occupying a position of self or subject, while Gollum's subjectivity is represented as inferior and devalued through his objectification by Bilbo as object or Other.

\section{The dream: a virtual encounter}

The Bilbo/Gollum encounter is preempted by Bilbo's nightmare premonition of danger, which is represented as a rupture and a widening chasm in the wall of the cave where the adventurers have sheltered overnight. Through the processes of Bilbo's dream production, the cave's floor destabilises, causing him to slip, fall and descend through this chasm, gap or liminal point 'down, down, goodness knows where' (1993, p.67) into a foreign, underground realm. This dream (as a virtual reality) causes an affect of fear, passivity and powerlessness in
Bilbo, as 'he was very afraid but could not call out or do anything but lie and look' (p.66).

In this representation, Tolkien utilises the Freudian model of dream production 'that consists essentially in the transformation of thoughts into a hallucinatory experience' (Freud 1991, p.219), to introduce motifs whose encoded meanings are repeated, expanded and increase in intensity during the ensuing (literal) encounter between these two protagonists. The motifs pre-empted at this textual site include and to some degree, superimpose the following: a mythical underworld journey; the psychic model of the unconscious; theological notions of the fall; and the specificities and fragmentary processes of the infantile (in particular, the prelinguistic) period of human development. An analysis of these motifs at this site destabilises The Hobbit's ideological assumptions by exposing the text's inherent (but unacknowledged) contradictions regarding its own representation.

\section{Crossing the limit}

After Bilbo's dream, the adventurers are abducted from the external world into the labyrinthine space of GoblinTown. In the ensuing action, Bilbo experiences his first, complete separation from his companions. In an expulsive, metaphoric birthing passage, Bilbo descends to the home of 
Gollum through a tunnel of infinite length that 'seemed to have no end' ( $p .76$ ). While propelling himself through this passage, temporality and spatiality are distorted and defamiliarised through acceleration and distance. Bilbo perceives the tunnel's passage as extending 'all the way to tomorrow and over it to the days beyond' (p.76). Having crossed this limit, this dividing line demarcating differing worlds, Bilbo becomes positioned in the field of his Other, that is, the place of alterity.

The locus/site of the encounter

The home of Gollum that Bilbo enters is represented as cavernous with 'a deep, dark, subterranean lake ... at the very roots of the mountain' (pp.76-77). As a stranger in a foreign land, Bilbo collates data about this environment based on sensory information which is encoded as a series of absences. Initially he experiences the absence of light (which is the presence of undifferentiated darkness), then the absence of sound (the presence of silence) while the atemporal (as eternal and resistant to human categorising of time) characteristic of this space is constructed by the primordial and intermittent 'drip-dripdripping' (p.76) of water 'from an unseen roof into the water below' (p.76). Gollum himself, as metonymic core, resides at the epicentre, the nucleus of this environment, 'on a slimy island of rock' (p.77).

The representation of this space as an undifferentiated, nonabstract void allows this location to be aligned with the Freudian notion of the uncanny which is 'undoubtedly related to what is frightening - to what arouses dread and horror ... [and] ... tends to coincide with what excites fear in general' (1917-1919, p.219).

Derived from the German term unheimlich, (whose semantic components are $u n=$ not and heim =home), the uncanny is a coincidence of opposites, meaning simultaneously home and not home. It also denotes the first home, the maternal womb associated with 'the phantasy ... of intra-uterine existence' (19171919, p.244). The uncanny is, paradoxically, both familiar and strange, its contents being distantly remembered, yet foreign and alien; in fact, it is frightening precisely because it is not known and familiar' (p.220). The encounter between Bilbo and Gollum, then, is an uncanny experience, as it occurs 'when infantile complexes which have been repressed are once more revived by some impression, or when primitive beliefs which have been surmounted seem once more to be confirmed' (p.249).

While being a receptacle for an uncanny experience, the structure and contents of Gollum's home also function as a metaphor of the psychic model of the unconscious. The structure of this locus as gap, cavity or hole is analogous with the Freudian unconscious which 'resides in the gap or instant between a perception's impingement on the nervous system and its (deferred) conscious registration' (Grosz 1990 , p.84). By privileging silence, darkness and an unfamiliar passage of time. Tolkien has represented what Terry Eagleton describes as

the extreme strangeness of the unconscious ... as a place and a non-place, which is completely indifferent to reality, which knows no logic or negation or causality or contradiction, wholly given over as it is to the instinctual play of the drives and the search for plcasure (1983, p.157).

\section{The representation of Gollum}

Gollum is introduced to the receiver of this text as 'a small slimy creature' (p.77) whose narrator is unable to divulge 'where he came from, nor who or what he is' (p.77). This representation, from the perspective of a de-contextualised reading of this text, is deeply problematic. Inscribed by Tolkien as a de-historicised Other, Gollum is represented as alterity without origin. This mode of representation - of effacing a subjective or racial past - is a form of epistemological violence 
that oppresses the voices, articulations, and conditions of possibility of particular forms of identity. The ideological assumptions offered in The Hobbit as pre-existing or given, effectively de-contextualise certain subjects and ethric groups by separating these individuals and collective groups from their respective social lives and histories. This colonising representation therefore justifies and rationalises its own ideological position as the natural order of things, so generalising, depoliticising and neutralising the specificities of difference or alterity within a 'universalising' totality or concept. By representing individuals and racial groups in this way, it is possible to reduce and restrict these subjects by binding them to stereotypical and mythological conventions and expectations regarding biological determinants (such as race). Gollum's unknown status (as Other) and his lack of origins also have political, in particular, antiSemitic, resonances. The representation of this textual character, posited as 'lost', 'wandering' and 'cursed', parallels the ideology or world view whose distortion and domination through force enabled the victimisation and subsequent holocaust experiences of the Jewish race during the World War II period.

'Slimy' and amphibian-like,
Gollum's body is a site of ambiguity, of indistinct and ambiguous borders. Neither matter nor fluid, his form is unable to be accounted for, or incorporated within, the categorising systems of Darwinian evolution. In relation to the post-Freudian theorisation of Julia Kristeva, Gollum may be likened to the abject, that which is 'in-between ... ambiguous ... [and] ... composite' (1982, p.4). Abject matter (that which is culturally taboo) is evasive and mobile; it resists categorisation and therefore cannot be considered in distinct terms of black or white but must be perceived as an indistinct shade of grey, or as the hazy area between absolute values or binary opposites.

The tautological description that Gollum is 'as dark as darkness' (p.77) is an ambiguity, a destabilising representation that evades and resists definition. This description has postcolonial (by implicating black-skinned racial types) and philosophical implications as to the nature of human interactions - are human relations of power always

dependent on the existence of a Master and the subservience of a slave? If so, what is the purpose of civil and human rights movements and why would/should black (and other) consciousness movements challenge conventional social and cultural paradigms throughout human history?
The abject subject, according to Kristeva, causes fear, suspicion and guilt. Like the laundering of dirty linen in public, this type of subject can be considered a manifestation, or a symptom of repression. In the presence of the abject (Gollum) the unconscious (Bilbo) functions by exclusion. This is most evident in Tolkien's allusion to Greek mythology, for Gollum 'had a little boat, and he rowed about quite quietly on the lake .... He paddled it with large feet dangling over the side, but never a ripple did he make" (italics mine) (p.77). In this way Gollum, as ferryman, navigates his boat across a rippleless river (the Styx), carrying those with whom he interacts to Hades (the ancient Greek Underworld), or death. This example of the unmentionable, which is the contemporary taboo of death, causes an affect of fear in Bilbo, because death, like abjection, is the taboo about which most people would prefer not to think.

In this way, Bilbo's journey metaphorises the physical passage of birth, while it also alludes to cultures and myths where narrative heroes (and victims) descend 'into the underworld to confront death itself' (Leeming 1990, p.43). In this context, death can be perceived as 'a passing from one kind of time to another - from life yesterday to life tomorrow. What is in the Underworld belongs to death, but is in a state of 
becoming ... Life can be seen, becoming is hidden' (Leeming 1990, p.65). The Underworld involves organic processes of composition and decomposition, it evokes the notion of renewal; of becoming, and as such it is characterised by the field of the material. Furthermore, materiality and abjection are unacknowledged and repressed by, yet are essential to, Western culture.

Bilbo perceives Gollum as his uncanny double, a 'harbinger of death' (Freud 1917-1919, p.235), whose 'doubling, dividing and interchanging of the self' ( $p .234$ ) disturb Bilbo's sense of order regarding his life and selfidentity. This is because the uncanny double entails primitive fears of the dead, the risk of possession, of having one's life 'stolen', or being made redundant by another. As an abject subject, Gollum represents Bilbo's fear of death as an unknown, frightening void, or as a contaminant which is able to modify unpredictably Bilbo's present and his future. This perception of the body and of death is a historical and cultural assumption that also implicates identity. That is, 'owing to the discoveries of Pasteur, people had become obsessed with hygiene. Where death had once been a part of life, now it came to be seen as a form of decay' (Perrot 1990, p.333). Death and alterity were therefore perceived as agents of disease or corruption and were considered capable of destabilising or contaminating (social/individual) identity. This assumption may be deconstructed to reveal that subjectivity and textuality are not 'given', but are processes or modes of becoming which are capable of modification or of being 'contaminated'. In this way identity - or the social

constructedness of the self cannot be considered innate, stable, fixed or immutable, for it is constantly formed and re-formed and hence able to be altered.

Through his language use and mode of (self) address, Gollum's identity is represented as mobile and heterogeneous, as he occupies both subject and object position by using the first-person form 'my precious' (p.78) and the proper noun, 'Gollum' (p.78) when speaking. This dialogue implies a narcissistic relationship of the self to the self where Gollum is the centre of, and constitutes, his own universe, knowing no social world outside his own boundaries. Gollum, 'who alway's spoke to himself through never having anyone else to speak to' (p.78) is depicted as the subject of a past and ongoing narcissistic crisis, which occurs when a subject regresses to an earlier, remembered state, where the external world is excluded (see Kristeva 1982, pp.13-15). Characteristic of this regressive place of development, this internal haven, is the autoeroticism of one's body as an object, which is also the subject, of one's own desires. Gollum's transgressive identity (transgressive because it is excessive and unrepressed) may also be traced to an earlier, regressive state of development. This reveals Gollum's infantile sexuality as another aspect of the Bilbo/Gollum uncanny double relationship which is textually represented as a site of fear and repression. This is because infantile sexuality invoives a certain lack of bodily control, a powerlessness associated (through undeveloped bodily processes and lack of motor coordination) with the infantile period.

Gollum's infantile sexuality cannot be accepted or incorporated by Bilbo because it represents a significant threat to him, for the return of repressed infantile complexes has the ability to destabilise Bilbo's belief in his own individual and unified (self) identity. In Freudian terms, however, the infantile period is not characterised by notions of unity or wholeness, but is based instead on a plurality of stimulations and excitations from non-specific (or non-privileged) erotogenic (bodily) sites. The infantile period is therefore defined by Freud as polymorphous perversity, because the sexuality of infants lacks a single, distinct or unified sexual aim, object or 
function; as such it is constituted almost exclusively in terms of tactile stimulation in the form of autoerotism. The satisfaction, pleasure or happiness of children in the Freudian terrain is pluralistic, knowing more ways than one for satisfaction. As Bilbo is unable to accept the becoming, the formation of his own subjecthood through bodily processes, he therefore projects his insecurities, fears and anxieties onto Gollum as Other to himself. The sycophantic language used by Gollum to address Bilbo, as well as Gollum's fear that the loss of the ring (as an icon of power) will threaten the homeostasis of his present safety, again indicates the presence of a racial mythology which encourages the identification of Gollum as an archetypal Jew.

This representation of Gollum is further enhanced by the stereotype of the Jewish race as a mobile collective whose subjects are disrespectful of (social) interiority and exteriority. The Jewish race is stereotypically represented as contaminising, through the representation of Gollum as a 'thing' that has sneaked 'in from outside to lie up in the dark' (p.76), that is, as a racial group that 'does not respect borders, positions, rules' (Kristeva 1982, p.4). This positioning of the Jewish people as a mobile, uncontained group of subjects ideologically threatens Tolkien's world view, for this stereotype represents the Jews as a racial type that 'disturb[s] identity, system, order' (Kristeva 1982, p.4). The mobility of the abject, its disregard for boundaries and structures, is represented in the text through the naming of Gollum for the nasal sound he makes in his throat (see Ryan 1982, p.102). This titling indicates a manifestation, or return of repressed bodily substances, that the conscious mind (whose representative is Bilbo) would prefer remained sealed. As a referent to non-Anglo-Saxon language, Gollum's name also connotes hegemonic relations of power at the site of language; that is the assumption of linguistic and, by extension, racial superiority. The guttural phonemes of Hebrew/Yiddish speech, that is, the language of the Other are furthermore devalued in colonial discourse which attribute to the 'native tongue' connotations of inferior status, class and race.

Furthermore, by defining Gollum in reference to Bilbo, he is represented as that which he is not, that is, as Other, which is the representation of subjectivity through negation.

\section{The Riddle Game}

The exchange of riddles whose wager is Bilbo's very life, may be seen from a theological

perspective as embodying notions of temptation, sin, the fall and the differentiation between salvation and damnation. Embodying themes of knowledge and power, the 'riddle game ... [itself] ... was sacred and of immense antiquity and even wicked creatures were afraid to cheat when they played at it ${ }^{\prime}$ (p.84). Yet Bilbo cheats for the sake of his own survival, as his 'last question ... [in that exchange] ... had not been a genuine riddle according to the ancient laws' (p.84).

In the context of Tolkien's theology, which is necessarily related to, and dependent on, the cultural context in which it was produced, Bilbo transgresses the law (of Middle Earth), which positions him in this religious discourse as a sinner. Tolkien metaphorically depicts Bilbo in The Hobbit as 'Christian man' striving to resist temptation (like the original man, Adam) when endangered by seduction either by a subject, or an object, of desire. The Christian myth of the fall into original sin mirrors Bilbo's altered ontological status, as in this model, it is only through the experience of sin that human subjects can gain knowledge into their divided natures. Human duplicity in this discourse is therefore exemplified through an opposition between the terms resistance (that connotes rationality and the conscious mind, and implies repression) and $\sin$ (which involves matter, the corporeality of the body and transgression).

This doctrine, a dominant idea in Tolkien's time, grants primacy to 
the mind, which strives to attain redemption through deeds performed in the current life, so that the person may achieve salvation in the afterlife. As well, it sublimates the pleasures of the body (which are represented as transgressive if not regulated and controlled) through prohibitions or taboos which, if violated, entail the punishment of eternal damnation. In many ways, this model is similar to the repression or sacrifice of infantile (bodily) pleasures which must occur in order for a child to attain a position as an autonomous subject in the external (social) world. This theological and human developmental model, by demarcating a mind/body distinction, is unable to account for the multi-dimensional nature and function of desire, which is located both internally (in the psychic registers of the conscious and unconscious mind) and externally (through actions and attachments to external objects) to human subjects. Desire then is a flow, a current, a mediating force or term whose aim (pleasure) is excessive to biological survival and effects a provisional loss of a subject's identity. As a motivating force or current, desire functions not in isolation, or in dualistic terms (the mind / body division), but in a relationship of mutual reciprocity that interpenetrates both bodily and mental processes (the mind and the body) within and between subjects.
While Bilbo represents the resisting or repressing subject in The Hobbit, Gollum functions as a metaphor of desire. He is a desiring (or lacking) subject who also possesses an object of desire: a ring which is an icon of power but which entails the possibility of corruption on the part of its wearer. For Gollum, the riddle game represents the originary memories of his personal history, a time 'ages and ages and ages before, when he lived with his grandmother in a hole in a bank by a river' ( $p .80$ ). As such, this period alludes to Gollum's experiences prior to separation and alienation, to a time 'long ago before he lost his friends and was driven away, alone and crept down, down into the dark of the mountains' (p.78). Viewed from this perspective, Gollum's participation in the riddle game involves memory recall as it retrospectively (re)presents Gollum's pre-history, his experiences prior to his division and separation from family and society, indeed, before his marginal status (as an underground, fallen, 'damned', isolated or alienated subject) had been realised.

In relation to the narcissistic subject, this information points to maternal deprivation and/or infantile trauma as a formative influence in the constitution of subjecthood. The narcissist tries to fill the void of its perceived lack or loss, not by assimilating with others, but by focusing instead on the establishment of an internal, self-sufficient universe constructed by, and for, the self. In this way, Gollum can be perceived as a socially produced subject whose selfdetermination is constructed and defined through his processes of ego defence. As a deprived, lacking subject experiencing loss, Gollum's subjective experiences can be considered analogous to the human condition (of lack and loss) which ought to encourage the values on which are predicated Tolkien's Christian theology: notions of empathy, charity and compassion for those suffering or in need.

The individual riddles themselves metonymically represent the composite parts of each character's experiences which have formed (and whose processes continue to form) their respective identities. The meanings of the riddles (as they connote knowledge and power) are, inevitably, value-laden, and must be considered in terms of the power relations presupposed by any ideology and in relation to the responses of a marginalised or a central subject position: the practice of accepting or resisting stereotypes or myths. Bilbo's riddles encapsulate the repository of his life experiences and can be perceived as relating to pastoral themes and notions of fertility and plenitude, metonymically represented through the symbols 
of chestnuts, the sun, eggs and legs. Gollum, in contrast, is referred to in material or elemental terms, which designate his existence in relation to mountains, wind, darkness, fish and time.

Gollum's dialogue in the riddle game again patterns relations of power, as the elemental aspects of Gollum's form intertextually refer to the Jewish folkloric myth of the Golem. As a precursor to the Frankenstein narrative, the tale of the Golem, which originated in the ghettos of Prague, conflates Jewish mystical knowledge (the cabbala) with the answer to the riddle of life and death, which is based on the human control and regulation of supernatural forces. Created from clay by a Jewish rabbi, brought to life by the tracing of the words 'Shem ha-me forasch, the pre-eminent name of God' on its forehead (Bloch 1972, p.34), the Golem's mythical function is to protect persecuted Jewish people throughout history. As a supernatural being subject to human, rule-governed practices, the Golem is resurrected daily by the inscription of the word Shem (the Jewish equivalent of the life principle) on its forehead (Bloch 1972, p.35), and is deactivated nightly, or when the Golem's services are not required, by the erasure of this word. This myth also suggests that the power of the Golem as a supernatural being (functioning, or malfunctioning, within the parameters of its operating conditions) is potentially unpredictable and, as such, it can never be fully or totally controlled by human actions.

This reference to the Jewish Golem myth has a paradoxical signification or meaning. For, although constructed to protect persecuted Jews, the Golem is also eternally bound to serve these people. He is therefore both the eternal protector and an eternal victim of the Jewish race. The Golem, in its form and intended function, embodies a divided power relationship, a duality, at the site of its own existence. The Golem is a useful servant (able to be constructed and exploited) when utilised appropriately, yet he is also a figure of fear, for this enslaved creation can unwittingly resist its creators' intentions by unpredictably 'going crazy'. The Hobbit's assimilation of the Jewish Golem myth may then be read as a symptom of the anxieties and fears of Tolkien and his society, regarding postindustrial, colonial, genetic and other socio-political creations or constructs chaotically determining themselves independent of, or resistant to, their creator's plans or wishes.

\section{The ring as leveller}

The ring in The Hobbit functions textually as a mediating link, or a middle term, that unites Bilbo and Gollum. It represents a shared aspect or inner doubleness, suggesting that these two characters may in fact share more similarities than differences. As an object, the ring, with its associated power and invisibility functions, fascinates (from the Latin term, fascinali , 'to bind') both Gollum and Bilbo. Only at the end stage of their encounter, when Gollum realises the loss of this object (which Bilbo has appropriated), is Gollum's curse, which is the desire to retain an object of beauty and power, identified by Bilbo. As a direct response to Gollum's laments, Bilbo experiences interpersonal feelings which are depicted in the text as the mental processes of 'understanding ...[and] ... pity mixed with horror' (p.90). This sensation of horror, although ostensibly prompted by Gollum's cries, may also represent Bilbo's introduction to knowledge or experience, which is represented by feelings of shame and guilt (as he is directly implicated in, or is, to, some degree, responsible for, Gollum's pain). Shame and guilt are also conspicuous aspects of colonial discourse, as these attitudes are commonly displaced or transferred onto colonised people. As an object of desire, then, the ring further levels the power dynamic between these two characters, as Bilbo himself experiences a parallel moment of anguish, a 'pang of fear and loss, like an echo of Gollum's misery' (p.92) when confronted with the 
possibility that he too may have lost this coveted object.

\section{Bilbo/Gollum parallels}

Despite Bilbo's inability to accept alterity in himself (which causes him to project or transfer his anxieties regarding his identity or perception of the world onto an external Other), there are throughout the text multiple points of intersection that align the characters of Bilbo and Gollum through (unacknowledged or covert) patterns of similarity. Although Gollum is overtly represented as possessing questionable origins, so too, are Bilbo's (adventurous, ancestral) origins obscure. Like Gollum, Bilbo is also a subject divided within his self: between the pleasure seeking id of the Tooks, and the domestically and socially sublimated existence of the Bagginses. Bilbo, as appropriator of the ring, is also at risk of being consumed, possessed and absorbed through his desire for the ring as an object of desire - which is highlighted by the symptom of his secrecy, his covetous retention of this acquired possession. $\mathrm{He}$ (Bilbo) cheats at the riddle game, yet transfers his negative emotions onto Gollum. Like the embryonic amphibian Gollum, Bilbo is also not fully formed, physically and psychologically, for he does not resist or question textual figures of paternal authority, and their assumed superiority over him. At the denouement of the adventure, Bilbo is also developmentally static, existing between the world of adveriture and a life of domesticity. Therefore, Bilbo's end position in the text parallels Gollum's geographical isolation and narcissistic stasis, as both characters (at some stage) are placed peripherally, or are marginalised from, their respective families and societies.

\section{Textual and ideological} criticisms and problems

While I don't wish to detract from the pleasure of Tolkien's text, which skilfully crafts and joins multiple mythological and narrative strands, its ideological and contextual assumptions, when read critically, do pose a number of problematic issues in relation to contemporary theorisation about culture and representation. A major criticism of the textual and contextual ideology of The Hobbit must be its structured, ordered, rigid and secure view of the worlci, a view whose homogeneous, 'meltingpot' model of representation subsumes abstract notions of difference, plurality and heterogeneity. To challenge this perception of the world, it is necessary to question by whose authority 'normality' or 'universality' are represented and whose interests (elite, powerful, socio-economic groups) these assertions benefit.

Co-extensive with this model, yet unacknowledged by it, is an assumption of racial superiority which constructs and perpetuates colonial mythologies and racial stereotypes. In this discourse, the representation of Gollum as an archetypal Jew must be considered problematic, as it entails a reductive racial stereotype that could be classified as anti-Semitic. This devaluing of particular racial or social groups in The Hobbit implicates relations of power founded on the premise that interpersonal and collective forms of human interaction have to entail a Master/Slave dichotomy. However, it is possible to challenge this textual contention by questioning the modes of operation that establish (contingent) power relations in society. Unlike the concluding Prospero/Caliban relationship in Shakespeare's The Tempest, Bilbo does not acknowledge Gollum, his 'thing of darkness' (1951, p.72) as complementary, or belonging to, his own inner nature. Is it not possible to reconfigure power as a dynamic, productive (as opposed to repressive) force that is open to individual and collective negotiation and re-negotiation? ${ }^{2}$

Another textual and ideological criticism of this work and Tolkien's context, is the positioning of the unconscious (and death) as a site of fear and repression. An index of this repression is the absence of central feminine characters, an 
absence which must be considered exclusionary and problematic in relation to contemporary social debate regarding the equality of biologically determined, sexually differentiated subjects. This point may be further clarified by an analysis of Tolkien's religious discourse as a set of regulatory, rule-governed practices which repress the bodily pleasures of infantile sexuality (which is the pre-condition for adult sexuality) by introducing external, social concepts of shame and guilt that effect a division, or separation, between the functioning of the mind and the processes of the body. So, despite the fact that the unconscious often contains frightening (as they are irrational) contents, it is also capable of stimulating works of human ideals and endeavour. In other words, we all experience the fear of nightmares, but we also gain pleasure, insight and motivation from the processes of the imagination and the production of some dreams.

From the perspective of suffering and the sacrifice of human life, Tolkien's militaristic themes are also a point of contention and contestation. The political implications and unmeasurable social consequences of representations that valorise force in the attainment of individual, racial, religious or nationalistic goals, must be interpreted from a critical perspective. This final criticism then, challenges the adjudication of what constitutes enemy, while critiquing the justification or naturalisation of violence once that category has been defined.

\section{Notes}

1. This model uses Foucault's genealogical approach to question the validity of specific truths within a historical epoch as codes that are agreed upon (either implicitly or explicitly) in a particular social context.

2. Foucault formulates relations of power as mobile, productive and constructive operations that interrelate in a multitude of ways. For Foucault, power 'doesn't only weigh on us as a force that says no, but ... it traverses and produces things, it induces pleasure, forms knowledge ... [and] ... produces discourse[s]' (1980, p.119)

\section{References}

Barthes, Roland (1972) 'Myth today', in Mythologies. London, Vintage, pp.109-127.

Bloch, Chayim (1972) The Golem: Mystical Tales from the Ghetto of Prague. New York, Rudolf Steiner Publications.

Curtis, Jared (1984) 'On re-reading The Hobbit, fifteen years later', Children's Literature in Education 15 2, 113-120.

Eagleton, Terry (1983) Literary Theory. An Introduction. Oxford, Basil Blackwell.
Foucault, Michel (1980) Power I Knowledge. New York, Pantheon.

Freud, Sigmund (1917-1919) 'The Uncanny', in The Standard Edition of the Complete Psychological Works of Sigmund Freud, Volume XVII. London, The Hogarth Press. Freud, Sigmund (1991) 'WishFulfilment', in Angela Richards (ed) Introductory Lectures on Psychoanalysis. London, Penguin, p.250.

Grosz, Elizabeth (1990) 'The

Freudian unconscious', in Jacques Lacan: A Feminist Introduction. Sydney, Allen and Unwin.

Kristeva, Julia (1982) Powers of Horror. An Essay in Abjection. New York, Columbia University Press.

Leeming, David (1990) The IVorld of Myth. New York, Oxford

University Press.

Perrot, Michelle (ed) (1990) A

History of Private Life: From the Fires of Revolution to the Great War. London, The Belknap Press of Harvard University Press.

Ryan, J. (1982) 'Gollum and the Gollem: A neglected Tolkien association with Jewish thought', Orana, 18, 3, 100-103.

Shakespeare, William (1951) The Tempest. London, Collins.

Tillyard, E. M. W. (1946) The

Elizabethan World Picture. New York, Vintage.

Tolkien, J. R. R. (1993) The Hobbit. London, Allen and Unwin.

\section{Biographical Note}

Rachael Cameron is a playwright, fiction writer, poet and academic. Currently she is completing her Graduate (Honours) year in English and Comparative Literature at Monash University, Clayton campus. 